\section{(C) OPEN ACCESS}

\title{
Murmur clinic: validation of a new model for detecting heart valve disease
}

\author{
Jane Draper, Sheila Subbiah, Rikki Bailey, John B Chambers
}

Cardiothoracic Centre, Guy's and St Thomas' Hospitals, London, UK

\section{Correspondence to} Professor John B Chambers, Cardiothoracic Centre, St Thomas' Hospital, London SE1 7EH, UK; john.chambers@gstt. nhs.uk

Received 4 April 2018 Revised 1 July 2018 Accepted 2 July 2018 Published Online First 26 July 2018
Check for updates

(C) Author(s) (or their employer(s)) 2019. Re-use permitted under CC BY-NC. No commercial re-use. See rights and permissions. Published by BMJ.

To cite: Draper J, Subbiah S, Bailey $\mathrm{R}$, et al. Heart 2019;105:56-59.

\begin{abstract}
Objectives We aimed to determine if auscultation or a point-of-care scan could reduce the need for standard echocardiography (transthoracic echocardiogram (TTE)) in community patients with asymptomatic murmurs. Methods Requests from general practitioners were directed to a new murmur clinic. Auscultation and a point-of-care scan were performed by a cardiologist between 1 October 2013 and 31 December 2014 and by a scientist between 21 July 2015 and 9 May 2017. Results In the first phase (cardiologist), there were 75 patients, mean age 54 (56 women), and in the second phase there were 100 patients, mean age 60 (76 women). In the total population of 175 , abnormalities were shown on TTE in 52 (30\%), on point-of-care scan in $52(30 \%)$ and predicted on auscultation in 45 $(26 \%)(p=0.125 ; 95 \% \mathrm{Cl}-0.02$ to 0.29$)$. The sensitivity of auscultation was not significantly different for the cardiologist (91\%) as for the scientist (83\%) $(p=0.18$; $95 \% \mathrm{Cl}-0.22$ to 0.175 ) and the specificity was $100 \%$ for both. Accuracy was $97 \%$ for the cardiologist and $95 \%$ for the scientist. For the point-of-care scan, the sensitivity, specificity, positive and negative predictive values and accuracy were $100 \%$ for both cardiologist and scientist.
\end{abstract}

Conclusion Most patients in a specialist murmur clinic had normal auscultation and point-of-care scans and no additional valve disease was detected by standard echocardiography. This suggests that a murmur clinic is a valid model for reducing demand on hospital echocardiography services.

\section{INTRODUCTION}

Heart valve disease is increasingly prevalent and a major cause of morbidity and premature death in all countries. ${ }^{12}$ Early identification and specialist follow-up allows timely referral for intervention and improves outcomes. ${ }^{34}$

Auscultating a murmur followed by echocardiography is the principle pathway for detecting valve disease in the community and is the second most common indication for open access echocardiography after suspected heart failure. ${ }^{5}$ However, auscultation by general practitioners has recently been confirmed to be both insensitive and non-specific for the detection of heart valve disease. ${ }^{78}$ Valve disease of any grade is found on echocardiography in less than one-third of patients referred from the community because of a murmur. ${ }^{5}$ Furthermore, standard echocardiograms (transthoracic echocardiogram (TTE)) take about $45 \mathrm{~min}$ to perform and are a relatively scarce resource. It has been suggested that a more limited 'point-of-care scan' taking $10-15 \mathrm{~min}$ can screen out patients not requiring TTE. ${ }^{8}$ This has not previously been investigated.

At our hospital, we developed a specialist murmur clinic for open access general practitioner requests indicated by a murmur. In a first feasibility phase, a consultant cardiologist performed both auscultation and the point-of-care scan, and in a subsequent phase these were performed by clinical scientists. This study compares results of auscultation and a point-of-care scan performed by a scientist or a cardiologist against TTE as the 'gold standard'.

\section{METHOD}

Patients referred for open access echocardiography by their general practitioner because of an asymptomatic murmur were booked into a once weekly afternoon session at Guy's and St Thomas' Hospitals. The first phase (consultant cardiologist) study was conducted as a feasibility exercise from 1 October 2013 to 31 December 2014 and the second phase (scientist) between 21 July 2015 and 9 May 2017. All patients had a standard study $(\mathrm{TTE})^{10}$ performed by a scientist (first phase JD, second phase RB) using a Vivid-7 system (GE Medical, Milwaukee, Wisconsin, USA). A pointof-care scan with the Vivid-7 system and auscultation were performed either before or after the TTE with no knowledge of the results of the TTE, in the first phase by a consultant cardiologist (JC) and in the second phase, when rostering permitted, by a clinical scientist (SS or JD). The point-of-care scan consisted of four views (parasternal long-axis and short-axis, apical 4-chamber and 5-chamber and subcostal) with imaging alone then added colour Doppler mapping. ${ }^{11}$ Auscultation was conducted in the four standard points and in intermediate positions with the patient at $45^{\circ}$ then at the left sternal edge with the patient sitting forward and at the apex and axilla lying on the left side. The clinical scientists had received training in auscultation with a cardiologist (JC) in a specialist valve clinic and at an MSc course run by Swansea University.

\section{Analysis}

Auscultation was classed as normal if there was no murmur heard or a likely benign systolic flow murmur (soft, short ejection systolic murmur with a well-heard second sound). Auscultation was classed as abnormal if there was a loud, long ejection systolic murmur or a soft, or absent second sound or a pansystolic or diastolic murmur. The point-ofcare scan was classed as normal if there was no more 
Referred for open access echocardiography

for murmur July 2015 to May $2017(n=240)$

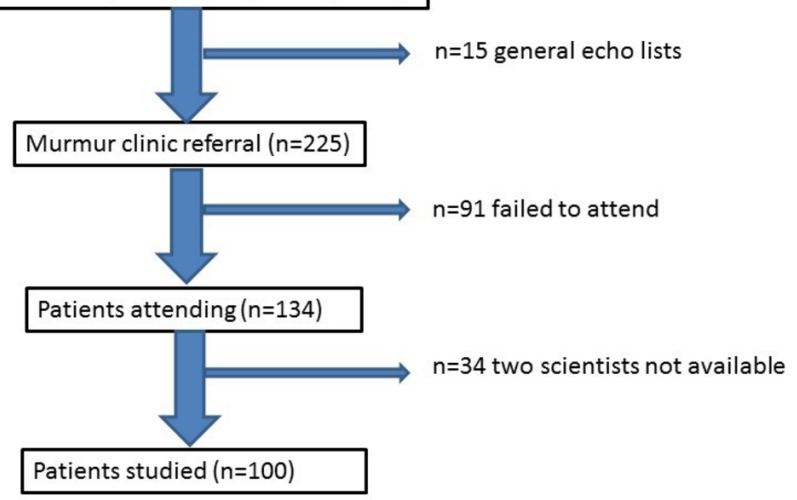

Figure 1 Consort diagram for the second, scientist phase of the study.

than minimal thickening or trivial regurgitation. It was classed as abnormal if there was anything more than mild thickening or trivial regurgitation. The TTE was classed as: normal, mildly abnormal (advised to have serial TTE after 3 years as per international guidelines), ${ }^{12}$ moderately abnormal (offered follow-up in a specialist valve clinic) and severely abnormal (requiring an immediate cardiology opinion). For the purposes of comparison with auscultation or point-of-care echocardiography, the three grades of abnormal (mild, moderate and severe) were combined.

Mean age was calculated. The sensitivity, specificity, positive and negative predictive values, accuracy and positive and negative likelihood of auscultation and point-of-care scans against standard echocardiography were calculated. Comparison of results for auscultation and point-of-care scans against standard TTE was with a two-tailed exact McNemar's test. The results of auscultation between scientist and cardiologist was with a two-sided Fisher's exact test. Calculations were performed using Stata V.14.2. Costs were estimated using the current National Health Service tariff of $£ 81.73$ for a standard simple echocardiogram in an adult. An estimate of $£ 27.24$ was made for a pointof-care scan since three can be performed in the time taken for one standard study.

\section{RESULTS}

In the first phase (cardiologist), there were 75 patients (56 women and 21 men) mean age 54 (range 20-94) years. In the second phase (scientist), there were 100 patients ( 76 women and 24 men) mean age 60 (range 22-92) years. Recruitment was slow because 91 patients failed to attend appointments and two scientists could not be released for every murmur clinic because of general departmental demands (figure 1).

\section{Results of TTE, auscultation and point-of-care scan}

Results were similar in both phases. In phase 1 , abnormalities were detected on TTE in 23 (31\%), on the point-of-care scan in $23(31 \%)$ and on auscultation in $21(28 \%)$. In the second phase, abnormalities were detected on TTE in 29 (29\%), on the point-of-care scan in $29(29 \%)$ and on auscultation in $24(24 \%)$. By comparison with TTE (30\%), the proportions for the total population detected by point-of-care scan (30\%) or auscultation $(26 \%)$ were not statistically significantly different $(p=0.125$; 95\% CI -0.021 to 0.288 ).

Comparisons of auscultation and point-of-care echocardiography against standard echocardiography are given in table 1 . Auscultation by the cardiologist was slightly more sensitive than by the scientists (91\% vs $83 \%$ ). This difference was not statistically significant $(\mathrm{p}=0.184 ; 95 \% \mathrm{CI}-0.022$ to 0.175$)$, although the wide $95 \% \mathrm{CI}$ indicated that equivalence of cardiologist and scientist auscultation was not proved. There were no differences for point-of-care echocardiography performed by cardiologist or scientist (table 1).

For both phases combined, the severe abnormalities detected were severe aortic stenosis $(n=4)$; the moderate abnormalities were moderate aortic stenosis $(n=10)$, moderate aortic $(n=3)$, mitral $(n=3)$ or tricuspid regurgitation $(n=3)$, left ventricular (LV) hypertrophy $(n=7)$ and LV systolic dysfunction $(n=1)$ and the mild abnormalities were mild aortic stenosis $(n=9)$, mild aortic $(n=6)$ or mitral regurgitation $(n=5)$ or a subaortic membrane $(\mathrm{n}=1)$.

The murmur clinic model with 52 TTE and 123 point-of-care scans would have cost $£ 7600$ (Euro 8637, US\$10 185) compared with the conventional model involving 175 TTE which cost $£ 14303$ (Euro 16253, US\$19 166). This represents a saving of 82 hours of scanning time and $£ 6703$ (Euro 7616 or US\$8981) based on current National Health Service tariffs.

\section{DISCUSSION}

This is the first published description of a specialist murmur clinic. The majority (70\%) of patients referred from the community with a murmur had structurally normal hearts and could safely have been screened using the limited views of a point-ofcare scan.

The sensitivity of auscultation by the scientist was $83 \%$ compared with $91 \%$ by the cardiologist, a difference that was not statistically significant although with wide $95 \%$ CIs reflecting the small population size. We estimate that a sample size of 580

Table 1 Comparison of auscultation and point-of-care echocardiography against standard transthoracic study as \% (95\% Cl) performed by a scientist or consultant cardiologist

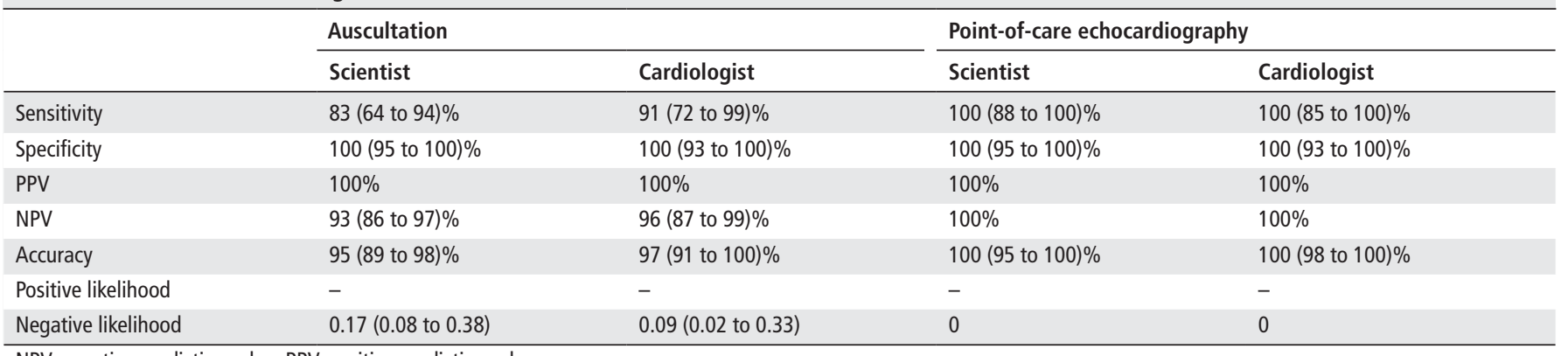

NPV, negative predictive value; PPV, positive predictive value. 
would be necessary to investigate equivalence between scientist and cardiologist with $80 \%$ power and assuming an acceptable difference in performance of $<5 \%$. By contrast, the point-ofcare scan had a sensitivity of $100 \%$ when performed by either scientist or cardiologist showing its superiority over auscultation for the detection of valve disease. ${ }^{8}$ We believe that auscultation should still be included in the assessment at a murmur clinic since a number of uncommon abnormalities (eg, muscular ventricular septal defect, aortic coarctation or pulmonary stenosis) would usually be associated with obvious systolic murmurs but might not be detected by a point-of-care scan. Conversely, diastolic murmurs as a result of mitral stenosis or pulmonary or aortic regurgitation may be hard to hear but should be obvious on a point-of-care echocardiogram. An abnormal murmur or pointof-care scan should prompt a TTE.

National workforce and organisational differences mean that the disciplines running a murmur clinic may vary. Often a cardiologist will run a murmur clinic either separately or within a specialist valve clinic, ${ }^{3}$ but in some countries, a specialist senior nurse might be trained for the role. In the UK, the cardiac physiologist career structure is now expanding with a Higher Specialist Scientific Training programme designed to produce a new class of consultant clinical scientists. A murmur clinic is consistent with the extended clinical role expected of this discipline.

\section{Comparison with existing literature}

Point-of-care scans have been shown to be safe and effective in acute medical presentations ${ }^{13-15}$ but have not previously been examined in patients with a murmur, although their use has been suggested in an international opinion paper. ${ }^{9}$ We found that only $30 \%$ of patients with an asymptomatic murmur had any grade of valve disease which is similar to the $29 \%$ and $31 \%$ frequencies shown in large series of open access echocardiograms in the $\mathrm{UK}^{5}$ and Holland. ${ }^{6}$ This is also consistent with recently published work ${ }^{7}$ showing that auscultation by general practitioners has a sensitivity of only $44 \%$ and specificity of $69 \%$ for the detection of significant valve disease on TTE. In an analysis of open access echocardiography, ${ }^{5}$ we detected significant valve disease in 127 (18\%) of 706 patients referred because of a murmur but in 267 (15\%) of 1745 patients when we extended the indications for echocardiography to include a potentially cardiac symptom, or atrial fibrillation. Furthermore, descriptive surveys ${ }^{16}{ }^{17}$ suggest that general practitioners may not have time to auscultate. A murmur auscultated by a general practitioner will remain important but echocardiography is the 'gold standard' for detection. A point-of-care scan would allow basic echocardiography to be more widely available to patients with any risk factor for valve disease including abnormalities on the history, examination or ECG or potentially age $>75 .^{7-9}$

\section{Clinical implications}

A point-of-care scan can be seen as an 'ultrasonic stethoscope"13 and is useful primarily as an extension of the clinical examination to reduce the need for relatively time-consuming and costly TTEs. The organisation of our clinic means that a TTE can be performed immediately if clinically indicated. Furthermore, not all clinicians requesting echocardiography may have competencies in the management of valve disease and the murmur clinic allows protocol-led application of agreed standards of care. ${ }^{12}$ Patients with moderate or severe valve disease are referred directly to a specialist valve clinic.

However, a community setting may be geographically more convenient for patients. This might increase the attendance
Key messages

What is already known about this subject?

- A murmur is a non-specific guide to the presence of heart valve disease but is one of the most common indications for echocardiography. This has significant resource implications.

\section{What does this study add? \\ - A normal standard echocardiogram can be accurately predicted by a point-of-care scan in a specialist 'murmur clinic'.}

\section{How might this impact on clinical practice?}

- Triage with a point-of-care scan could greatly reduce the need for standard echocardiography. A murmur clinic could apply evidence-based standards at local hospitals or within the community and refer only patients with significant valve disease to a specialist valve clinic.

rate since 91 (40\%) of 225 people invited to our clinic failed to attend. Those with normal scans would not need to travel to hospital and those with minor abnormalities requiring periodic follow-up could have this within the community. It would be possible to run community clinics with portable or hand-held devices $^{14}{ }^{18}$ which compare well against high-end machines for detection of valve disease. ${ }^{13}{ }^{14}$ However, it is essential that community-based systems have robust processes to deal with abnormalities including quick access to comprehensive TTE within a hospital-based specialist valve clinic.

Acknowledgements We thank Paul Seed, Senior Lecturer in Medical Statistics, Womens Health Academic Centre, KCL for statistical advice.

Contributors JD collected data in the first phase and wrote the first draft. SS collected data in the second phase, contributed to data analysis and contributed to revisions of the article. RB collected data in the second phase and contributed to the revision of the paper. JBC designed the study, collected data in the first phase and contributed significantly to the analysis of the data and to writing the finished draft.

Funding The authors have not declared a specific grant for this research from any funding agency in the public, commercial or not-for-profit sectors.

Competing interests None declared.

Patient consent Not required.

Ethics approval Trust audit office (number 5077).

Provenance and peer review Not commissioned; externally peer reviewed.

Data sharing statement There is no additional information.

Open access This is an open access article distributed in accordance with the Creative Commons Attribution Non Commercial (CC BY-NC 4.0) license, which permits others to distribute, remix, adapt, build upon this work non-commercially, and license their derivative works on different terms, provided the original work is properly cited, appropriate credit is given, any changes made indicated, and the use is non-commercial. See: http://creativecommons.org/licenses/by-nc/4.0/.

\section{REFERENCES}

1 Nkomo VT, Gardin JM, Skelton TN, et al. Burden of valvular heart diseases: a population-based study. Lancet 2006;368:1005-11.

2 Global Burden of Disease Study 2013 Collaborators. Global, regional, and national incidence, prevalence, and years lived with disability for 301 acute and chronic diseases and injuries in 188 countries, 1990-2013: a systematic analysis for the Global Burden of Disease Study 2013. Lancet 2015;386:743-800.

3 Lancellotti P, Rosenhek R, Pibarot P, et al. Heart valve clinics: organisation, structure and experiences. Eur Heart J 2013;34:1597-606.

4 Zilberszac R, Lancellotti P, Gilon D, et al. Role of a heart valve clinic programme in the management of patients with aortic stenosis. Eur Heart J Cardiovasc Imaging 2017; 18:138-44 
5 Chambers J, Kabir S, Cajeat E. Detection of heart disease by open access echocardiography: a retrospective analysis of general practice referrals. Br J Gen Pract 2014;64:e105-e111.

6 van Heur LM, Baur LH, Tent M, et al. Evaluation of an open access echocardiography service in the Netherlands: a mixed methods study of indications, outcomes, patient management and trends. BMC Health Serv Res 2010;10:37.

7 Gardezi SKM, Myerson SG, Chambers J, et al. Cardiac auscultation poorly predicts the presence of valvular heart disease in asymptomatic primary care patients. Heart 2018:heartjnl-2018-313082.

8 Otto CM. Mind the gap: missed valve disease diagnosis. Heart 2018:heartjnl-2018-313474.

9 Arden C, Chambers JB, Sandoe J, et al. Can we improve the detection of heart valve disease? Heart 2014;100:271-3.

10 Gardin JM, Adams DB, Douglas PS, et al. Recommendations for a standardized report for adult transthoracic echocardiography: a report from the American Society of Echocardiography's Nomenclature and Standards Committee and Task Force for a Standardized Echocardiography Report. J Am Soc Echocardiogr 2002;15:275-90.
11 Spencer KT, Kimura BJ, Korcarz CE, et al. Focused cardiac ultrasound: recommendations from the American Society of Echocardiography. J Am Soc Echocardiogr 2013;26:567-81.

12 Baumgartner $\mathrm{H}$, Falk V, Bax JJ, et al. ESC/EACTS guidelines for the management of valvular heart disease. Eur Heart J 2017;2017:2739-86.

13 Hothi SS, Sprigings D, Chambers J. Point-of-care cardiac ultrasound in acute medicine - the quick scan. Clin Med 2014;14:608-11.

14 Abe Y, Ito M, Tanaka C, et al. A novel and simple method using pocket-sized echocardiography to screen for aortic stenosis. J Am Soc Echocardiogr 2013;26:589-96.

15 Sicari R, Galderisi M, Voigt JU, et al. The use of pocket-size imaging devices: a position statement of the European Association of Echocardiography. Eur J Echocardiogr 2011;12:85-7.

16 Gaede L, Di Bartolomeo R, van der Kley F, et al. Aortic valve stenosis: what do people know? A heart valve disease awareness survey of over 8,800 people aged 60 or over. Eurolntervention 2016;12:883-9.

17 Webb J, Thoenes M, Chambers J. Identifying heart valve disease in primary care: differences between practice in Germany, France and the United Kingdom. European Journal of Cardiovascular Medicine 2014; III.

18 Fabich N, Harrar H, Chambers J. 'Quick scan' cardiac ultrasound in a high-risk general practice population. Brit J Cardiol 2016;23:27-9. 